\title{
Correction: Lopatin, E., et al. Assessment of Compliance with PEFC Forest Certification Indicators with Remote Sensing. Forests 2016, 7, 85
}

\author{
Eugene Lopatin ${ }^{1,2,+}$, Maxim Trishkin ${ }^{2,3,4, *, \dagger}$ and Olga Gavrilova ${ }^{5}$ \\ 1 Natural Resources Institute Finland, P.O. Box 68, Joensuu 80101, Finland; eugene.lopatin@luke.fi or \\ eugene.lopatin@forestrycloud.com \\ 2 Syktyvkar State University named after Pitirim Sorokin, Institute of Natural Sciences, \\ Oktyabrskiy Prospect 55, Syktyvkar 167001, Russia \\ 3 Faculty of Science and Forestry, School of Forest Sciences, University of Eastern Finland, P.O. Box 111, \\ Joensuu 80101, Finland \\ 4 Department of Geographical and Historical Studies, Faculty of Social Sciences and Business Studies, \\ University of Eastern Finland, P.O. Box 111, Joensuu 80101, Finland \\ 5 Department of Forestry and Landscape Architecture, Institute of Forest, Engineering and Building Sciences, \\ Petrozavodsk State University, Nevskiy Av. 58, Petrozavodsk 185030, Russia; ogavril@mail.ru \\ * Correspondence: maxim.trishkin@uef.fi; Tel.: +358-504-424-266; Fax: +358-29-4457-316 \\ + These authors contributed equally to this work.
}

Academic Editor: Timothy A. Martin

Received: 3 August 2016; Accepted: 8 August 2016; Published: 1 September 2016

The authors wish to make the following correction to their paper [1]. On page 9, the Acknowledgement Section should be corrected. The following sentence should be removed:

"The authors are grateful to the PEFC Collaboration Fund for opportunity to carry out pilot study in Finland; we would also like to thank PEFC Finland and, personally, Auvo Kaivola, who provided constructive comments and suggestions for the improvement of this article."

The authors would like to apologize for any inconvenience caused to the readers by these changes. The manuscript will be updated and the original will remain available on the article webpage.

\section{References}

1. Lopatin, E.; Trishkin, M.; Gavrilova, O. Assessment of Compliance with PEFC Forest Certification Indicators with Remote Sensing. Forests 2016, 7, 85. [CrossRef]

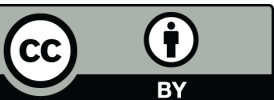

(C) 2016 by the authors; licensee MDPI, Basel, Switzerland. This article is an open access article distributed under the terms and conditions of the Creative Commons Attribution (CC-BY) license (http://creativecommons.org/licenses/by/4.0/). 